Universidad de Lima

Facultad de Derecho

Carrera de Derecho

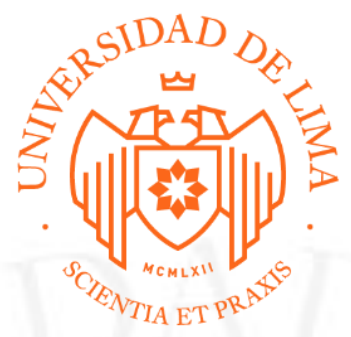

\title{
ARBITRAJE: "ARBITRAJE AD HOC" Y MINERO: "PETITORIO MINERO"
}

Trabajo de suficiencia profesional para optar el Título Profesional de Abogado

\author{
Alejandra Del Campo Farro
}

Código 20131768

$$
\text { Lima - Perú }
$$

Agosto de 2019 


\author{
ARBITRAJE: "ARBITRAJE AD HOC" \\ Materia: Arbitraje \\ No de Expediente: 1506-2012
}

\begin{abstract}
RESUMEN
En el presente expediente se analiza un arbitraje ad hoc de derecho que versa sobre la correcta entrega de obra en el marco de la Ley de Contrataciones del Estado. Sin perjuicio de ello, en el expediente se realiza un análisis respecto del deber de revelación del árbitro y las consecuencias de su transgresión: la recusación.
\end{abstract}

\title{
MINERO: "PETITORIO MINERO"
}

Materia: Petitorio Minero

$\mathrm{N}^{\circ}$ de Expediente: DE - MINERO0022 RESUMEN

\section{RESUMEN}

El presente expediente versa sobre un petitorio minero superpuesto a un área natural protegida. Dentro de las discusiones más importantes que se discuten frente al Consejo de Minería tenemos un análisis respecto del momento oportuno para que el SERNANP realice el análisis de compatibilidad entre la actividad minera, así como la posible existencia de un vicio de motivación en las resoluciones emitidas por el INGEMMET y la posibilidad de haberse producido la ruptura de la predictibilidad o confianza legítima entre el MINEM y el administrado. 